\title{
Media Literacy and Forms of Communication of Pupils with Disabilities
}

\author{
Bozena Supsakova \\ Comenius University, Faculty of Education, Bratislava, Slovakia
}

\begin{abstract}
Our objective was to study the level of media literacy in children of early school age, i. e. pupils in the first grade of primary school. We focused on the pupils with disabilities, namely learning disabilities (LD) who are either integrated in a general classroom with other pupils (school integration), or are part of a special class for pupils with $L D$ within the primary school. Another subgroup consisted of pupils with communication impairment (CI) either attending primary school for children with CI, or integrated in a general classroom with other pupils. The results confirmed without any doubts that our respondents have expanded their communication options and use the modern forms, such as the internet calls, chats, e-mails, etc. We can state that the pupils with disabilities did not have any significant problems with becoming familiar with the modern information-communication technologies and actively using them. Certain deviations can be noted for the following forms of communication: $41 \%$ of the pupils with CI favoured personal communication, compared to $31.4 \%$ of the pupils with learning disabilities. The opposite tendency applied to the use of mobile phones: while only $22.7 \%$ of the pupils with CI preferred this communication tool, it was $31.4 \%$ in the group of $L D$ respondents. We can come to the conclusion that the pupils with communication impairment can have certain problems with virtual communication without personal contact, when they cannot see the gestures and other forms of non-verbal communication that are an important source of information for them.
\end{abstract}

\section{Introduction}

To be media literate means that one has to acquire competencies and skills to be able to see the media and media content from a distance, yet on the other hand be able to make the most of the potential of the media as a source of information, education, quality entertainment and leisure activities.

The latest definitions of media literacy focus mainly on the target requirements of media literate persons: „Highly media literate individuals can place a content (message) in the context of a highly sophisticated knowledge structure, and are capable of multi-dimensional interpretation of any content. This gives them the ability to choose among several possible meanings". The well-known expert and author of Media Literacy, W. J. Potter, then says: "To become more media literate means seeing the boundary between the real world and the world that is produced by the media. Being media literate also means getting the information and experience you want, without getting out of the media what you do not want. Then you will be able to establish your life as you want, and do not allow the media to create it as it wants - on behalf of you". Media literate persons should have ,knowledge of how to use the media in their professional and personal lives, knowledge of the complex relationships between recipients and media content, knowledge of the dependence of media content on the social and cultural context in which they arise, knowledge of the commercial side of the media; knowledge allowing use of the media to communicate".

According to Hoechsmann and Poyntz: „media literacy is the summary of skills that allow us to interpret media contents and the practices of the media world to create our own media, to recognize and deal with the social and political impact of the media in everyday life" [6]. Taking into account the fact that media content (news, music, web sites, etc.) is produced by publishers and broadcasters, directors, film makers, and web designers, and is mediated by media channels and technology (television, film, digital technologies such as smart phones, mp3 players, tablets and digital cameras). In these and even other similar definitions the point of view of their authors referring to the period reflected by the author can be sounded. However, one unifying view is common to all of them: an appeal to raise media literate individuals who understand the media, can handle media products, ideas and mediated reality reasonably and autonomously. They can search, receive, analyse, assess, create and communicate the media and multimedia contents.

In the context of the above mentioned, our objective was to study the level of media literacy in children of early school age, i. e. pupils in the first grade of primary school. We focused on the pupils 
with disabilities, namely learning disabilities (LD) ${ }^{1}$, who are either integrated in a general classroom with other pupils (school integration), or are part of a special class for pupils with LD within the primary school. Another subgroup consisted of pupils with communication impairment $(\mathrm{CI})^{2}, 3$ either attending primary school for children with $\mathrm{CI}$, or integrated in a general classroom with other pupils. The basic set was composed of 50 pupils with disabilities -28 pupils with specific learning disabilities, mainly dyslexia, dysgraphia, dysortographia (16 of them boys) and 22 pupils with communication impairment (16 of them boys). These pupils came from all parts of Slovakia - the regions of Prešov, Košice, Banská Bystrica, Trenčín, Trnava, Nitra and Bratislava. Nine of the pupils with communication impairment also have been diagnosed with dyslalia, manifested by typical minor articulation problems, or incomprehensible articulation.

\footnotetext{
${ }^{1}$ The content of school education for pupils with learning disabilities when integrated within primary schools is, in fact, identical with the content for the first grade pupils. The only difference is that on the top of the basic subjects related to language and communication, the pupils with LD have two specific subjects - Individual Logopaedic Intervention and Development of Specific Functions (DSF). Educational Programme for Pupils with Learning Disabilities ISCED 1 - Primary Education and ISCED 2 - Lower Secondary Education. This educational programme, which is part of the State Educational Programme, was approved by the Ministry of Education of the Slovak Republic under No. CD-2008-18550/395821:914 on 26 May 2009.

2 "Pupils with CI attending a primary school for pupils with CI or a special class for pupils with CI follow a framework curriculum, which is part of this educational programme and compared to the framework curriculum of the general classes and schools; it only contains one extra subject, the Individual Logopaedic Intervention (ILI). Teaching methods and procedures are based on the results of the psychological and logopaedic diagnostics and an individual plan of logopaedic therapy." Educational Programme for Children and Pupils with Communication Impairment ISCED 0 - Pre-School Education, ISCED 1 Primary Education and ISCED 2 - Lower Secondary Education). This educational programme, which is part of the State Educational Programme, was approved by the Ministry of Education of the Slovak Republic under No. CD-2008-18550/39582-1:914 on 26 May 2009, p. 9-10.

${ }^{3}$ In compliance with the state educational documents and recommendations of professional institutions, the teacher creates the basic conditions for education, accepts the pupil with communication impairment and respects the specifics of his or her personality... In: Educational Programme for Children and Pupils with Communication Impairment ISCED 0 - Pre-School Education, ISCED 1 Primary Education and ISCED 2 - Lower Secondary Education).
}

The level of media literacy was assessed using an electronic questionnaire with 10 open-ended and close-ended questions. Another tool was a semistructured interview, where the responses and attitudes of the pupils with learning disabilities, integrated in the classrooms with other primary school pupils (in the charts and texts referred to as the pupils with LD), were analysed. The second group consisted of pupils with communication impairment (in the charts and texts referred to as the pupils with CI). Our objective, inter alia, was to find out whether there were any significant differences in terms of media literacy between these two groups of pupils. We were thus looking for similarities and differences based on the preferences of the children from both surveyed sets.

\section{Analysis and interpretation of acquired data}

The first question was to find out whether the children of early school age listened to radio and how much time they spent doing so. In general, we found that about one-third of the pupils did not listen to radio broadcasting. As shown in the Figure 1a, 1b, there was one obvious difference: up to $50 \%$ of the pupils with communication impairment did not listen to radio at all. This ratio was significantly lower in the pupils with learning disabilities - only $25 \%$. We can suppose that no listening to the radio receiver in the group of CI students is related to the problem of correct comprehension and interpretation of media messages which are mediated by spoken word and sound as pupils are not able to imagine real situations under the meaning of words in ether.

Another important deviation appeared in the time span of listening, in the case of listening for more than 2 hours a day. It is surprising that in this case the pupils with CI listened to radio more than the pupils with LD - $13.6 \%$ compared to $3.5 \%$. This finding can be explained by the fact that there are fewer children who like radio broadcasting, especially music programmes. A certain kind of current music on radio (hip-hop, rap, techno) impresses the pupils with CI with its style, dynamics and rhythm. 


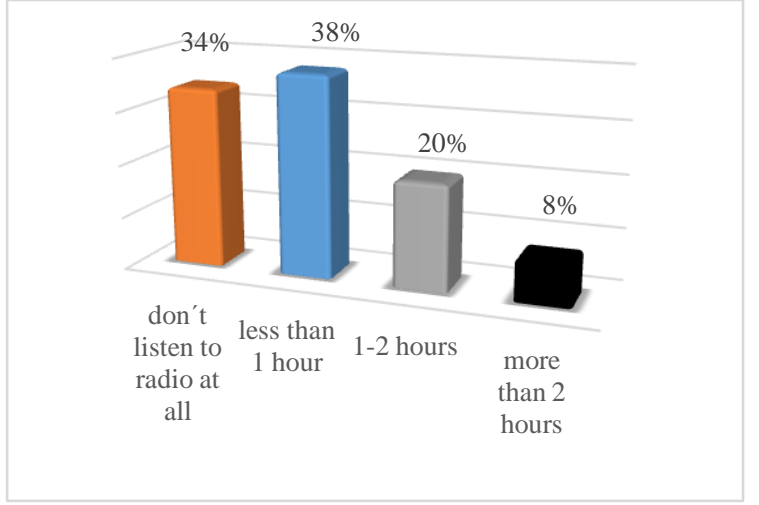

Figure 1a: Cumulative sum of daily listening to radio: the pupils with communication impairment and the pupils with learning disabilities.

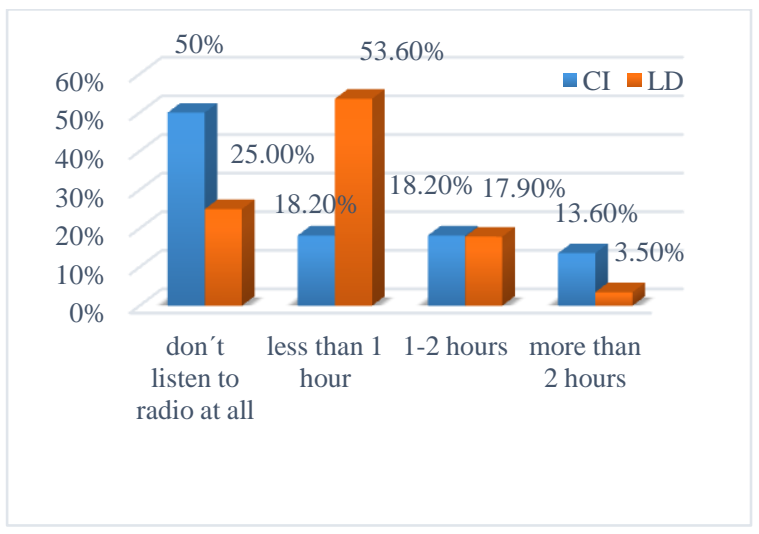

Figure 1b: Daily listening to radio: the pupils with communication impairment $(\mathrm{CI})$ and the pupils with learning disabilities (LD).

This indicates that children are generally not very interested in radio broadcasting. In both surveyed sets, one-third of children did not listen to radio at all and almost one-half listened to it for less than one hour a day. We can state that the needs of the young generation are fully saturated by the modern information and communication channels, notably the internet and social networks, mainly when it comes to music, which was the principal reason for listening to radio in the past.

Generally, the analysis confirmed that the rate of radio listening in children of early school age and the young generation as such has been declining over the last decade. This has been caused by modern information and communication media, notably the internet and recently also the social networks, which absorb a considerable portion of the free time of children and youth.

Television continues to be a phenomenon in the leisure activities of children. For the healthy population of children it is a long-term standard to watch TV programmes for two and more hours a day. This trend was similar in the pupils with communication impairment as well as the pupils with learning disabilities (Figure 2a, 2b). Children are attracted to this medium mainly due to the fact that it offers entertainment and comfort without requiring any activity or effort. In our survey, a number of children stated that the best thing about the television is that:

„(...) You can only sit in front of the screen and do not have to do anything. It is funny and comfortable."

„(...) Home comfort, I do not have to dress nicely and can rest at home. I watch what I want."

„(...) There are funny programmes, and also such, where you can learn something, for example about animals and nature. I am terribly bothered by advertisements, mainly when they are on too often."

In the group of the pupils with learning disabilities all of the children stated that they watched television every day. Only $4.5 \%$ of the pupils with communication impairment did not watch television at all. Up to $59 \%$ of the pupils with CI watched television for two or more hours a day and over $36 \%$ of them watched television for 180 minutes or more. This rate is slightly higher for the pupils with LD $-21.4 \%$ of them watched television for two to three hours and almost $43 \%$ for more than 3 hours a day. It can be summed up that there were not any particular differences between the two groups of pupils when it came to daily watching of television.

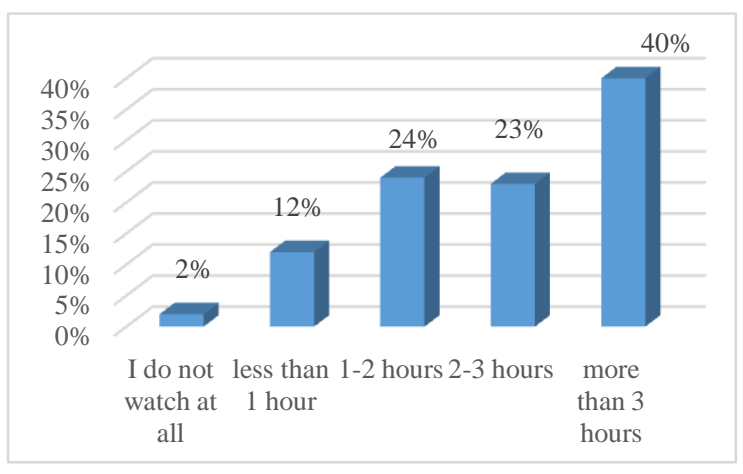

Figure 2a: Cumulative sum of daily television watching: the pupils with communication impairment and the pupils with learning disabilities 


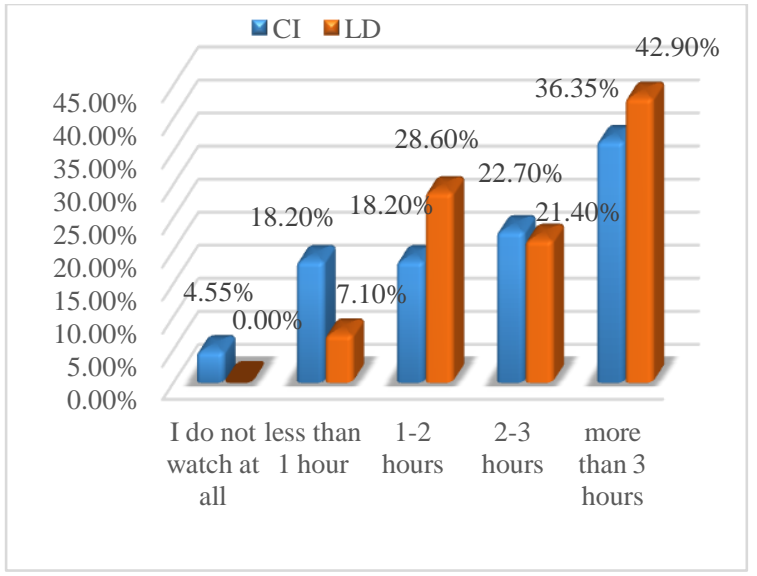

Figure 2b: Daily television watching: the pupils with communication impairment and the pupils with learning disabilities.

Television is an important socialising factor, as it affects the values, attitudes and behaviour of each individual. This study confirmed that it is a universal phenomenon for all children of early school age. Regardless of whether we consider the pupils in the first grade of primary school, the pupils with learning disabilities or the pupils with communication impairment, television was still the most preferred medium. However, our findings showed significant differences in terms of the time spent in front of television. In the case of the pupils with communication impairment $59 \%$ of whom watched television for more than 2 hours a day), we could argue that this group has problems with social adaptation, therefore they are seeking a stronger social status and self-fulfillment alone, in front of the screen. This ratio was even more significant in the pupils with learning disabilities $-64 \%$ of them watched television for more than two hours a day. Their responses suggest that television makes them forget about their failures at school and by identifying themselves with the main characters they boost their confidence. At the same time, they are spending time on an activity that is more satisfying for them than learning.

The semi-structured interviews showed that children watched mainly the Minimax and Disney Channel, within a wide offer of TV programmes for children broadcast during the whole day. They preferred cartoons to films for children. Their favourite programmes were The Simpsons, Tom and Jerry, The Ice Age, The Lion King, Martha Speaks and The Penguins of Madagascar. Although The Simpsons is a cartoon intended more so for adults, it also has features attractive for children. In their opinion it is an original story with fictional yellow characters and humorous dialogues:
„(...) They are funny, I like their stories, dialogues and also how they look like."

„ (...) Bart. And I like the beginning, when he is skateboarding. I also have a skateboard. And there is also a bicycle and a car."

„(...) I like the characters and the background and the way it is drawn. And how they talk... I especially like Bart, and Marge. I like Marge because she has blue hair."

„(...) What they are saying, they are funny and entertaining. I find them very amusing. Bart is my favourite, he always gets into trouble."

„(...) They are droll. Bart is the most popular. The most unpopular is Mr. Burns, because he is bad."

„(...) They are amusing and play pranks. They are yellow, that is a cheerful colour. My favourite character is Bart, because he does not listen to his parents. He always sneaks off."

Our survey further showed that the children do not have one favourite TV character with whom they identify on a massive scale. They liked a range of characters, besides Bart and Marge Simpson; they also have on their lists:

\section{(...) Tom and Jerry, „,because they are fun.”}

„(...) Tinker Bell, because she is brave and helps everyone."

(...) Spiderman, , because he fights against evil and saves people."

(...) The action hero Steven Segal, , because he is a good fighter."

Compared to television programmes for children, there was a high preference for TV shows broadcast after 8 p. m. Almost $20 \%$ of children of early school age stated in their responses that they regularly watch the evening shows. Besides the French feature film Asterix and Obelix they liked the Slovak series Búrlivé víno, Panelák and the German series Alarm for Cobra 11. That implies that children watch evening programmes that are not intended for them and often deal with ,adult problems“ and life situations. This finding also indicates that some of the parents allowed their children to „consume“ such programmes and thus often take inspiration from the negative patterns (broken relationships, aggression) that appear on the screen. Reality shows also had quite high viewing figures. Our survey showed that only about $10 \%$ of children did not watch this type of programme, while the others watched this type occasionally or regularly. The most attractive reality shows were Superstar (based on British „Pop Idol“), watched by approximately one-third of the pupils; 
one-fourth of them preferred Farma (The Farm), and $12 \%$ watched the Czech-and-Slovak version of „Got Talent".

When we asked them during the interview in which TV programme they would like to appear, the range of answers was very broad. Around 16\% of them would like to sing in Superstar, $10 \%$ of the children, mostly girls, would like to play in the series „Panelák" (,, The Block of Flats“).

\section{„(...) In Superstar, because I like singing. “}

„(...) In Batman, because I also want to fight against evil. “"

"(...) In the TV News, because I would like to be famous. "

\section{„ (...) In Tekken, because I am good at fighting. “}

Around $16 \%$ of the primary school pupils would not like to appear in any programme, which could mean that they are shy and self-conscious. $5 \%$ of the respondents did not answer this question. The pupils had an idea in which programme they would like to appear, however, their choices were diverse and based on personal preferences.

There is no doubt that the internet has become the phenomenon of this decade. It offers something that no other media have offered before: information and amusement, but also communication via social networks and all this in an integrated form under one roof. It does not matter whether one connects to the internet with a mobile phone, tablet, notebook or desktop. Due to high financial coverage, the prices of these end devices are already quite affordable, therefore they can be found in sufficient numbers also among early school age children. Again, in general, there were not any considerable differences between the respondents (Figure 3a, 3b). Almost all of them were already active on the internet and had the basic skills necessary for orientation in the virtual environment.

Our survey confirmed that up to $41 \%$ of the pupils with communication impairment spent between 2 to 3 hours online each day, which is nearly double the time spent by the pupils with learning disabilities at $22.27 \%$ (Figure 3a, 3b). It seems that the pupils with communication impairment were more attracted to the internet and found it more motivating. This could be explained by the fact that compared to the fixed programme structure of radio or television, here they have the chance to choose the content they prefer. From the perspective of content preferences, we noted that the pupils with communication impairment tended to be more attracted to online action games and YouTube videos than their peers with learning disabilities.

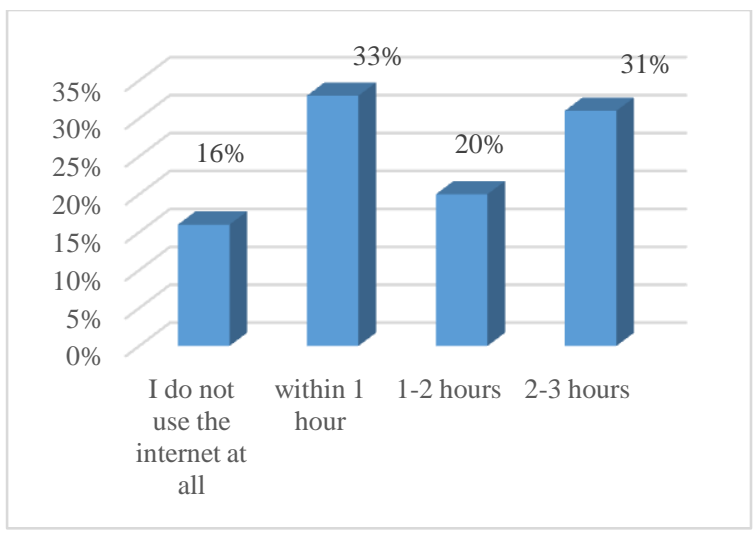

Figure 3a: Cumulative sum of daily internet use: the pupils with communication impairment and the pupils with learning disabilities.

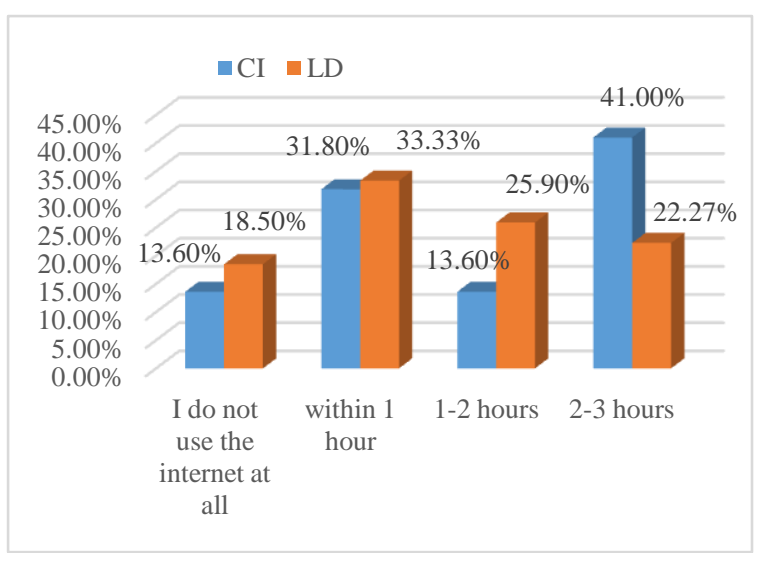

Figure 3b: Daily internet use: the pupils with communication impairment and the pupils with learning disabilities.

For the early school age children, the internet is the second most common mass information medium, right after the television, and thus it is the most preferred information-communication channel. This civilisation paradigm is generally accepted by all the children. Surfing the internet, communicating via email or even using social networks is so user-friendly and comfortable the children can manage it without any problems. We found only minimal and almost negligible differences in the numbers of respondents who did not use the internet as such: $13.6 \%$ of the pupils with communication impairment and $18.5 \%$ of the pupils with learning disabilities.

In the next question we asked our respondents without which medium they could not imagine their everyday life (Figure 4a, 4b). The evaluation of the responses did not lead to any surprising conclusions that would deviate from the generally-known trends from recent years. Other surveys have already confirmed that the three media and communication 
tools that are the most important for early school-age children are: television, mobile phone and internet. Both of the surveyed groups of pupils stated that they could not imagine their everyday lives without television, even though this preference was stronger in the pupils with LD, almost $40 \%$, compared to the pupils with CI, among whom only $24 \%$ said they could not imagine life without TV (Figure 4a, 4b). That confirms the above-mentioned statement that television was more popular among the pupils with learning disabilities.

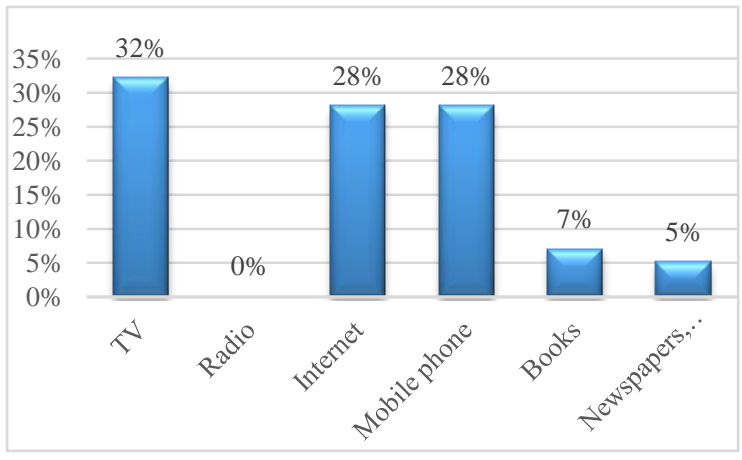

Figure 4a: Cumulative sum of preferred media and sources of information in everyday life: the pupils with communication impairment and the pupils with learning disabilities.

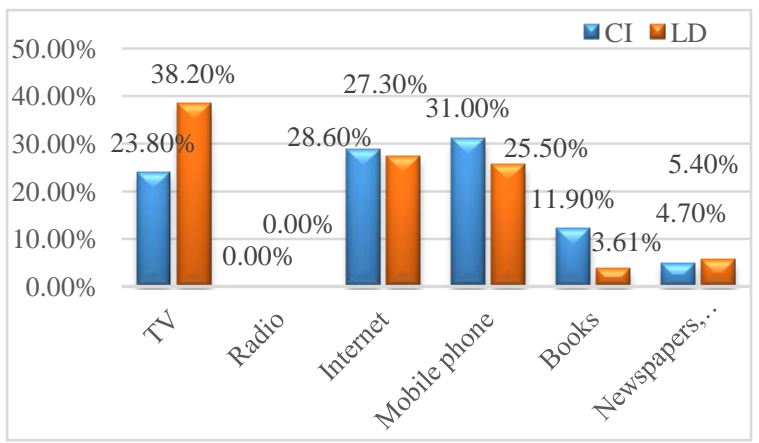

Figure 4b: Preferred media and sources of information in everyday life: the pupils with communication impairment and the pupils with learning disabilities.

As for use of the internet, the preferences of both groups were more or less similar, but the pupils with communication impairment had a distinctively bigger preference for books than the pupils with LD, $12 \%$ compared to $3.6 \%$. A possible explanation is that the printed and thus static text is more suitable for the pupils with CI. The books not only match their communication capacities and skills, but they also give the children more time to understand the content and its context. Television is a very quick medium with dynamic visual information flowing at a fast speed, which for the pupils with communication impairment can be hard to follow.

The evaluation of the preferences for respective media and sources of information yielded the expected results for the both surveyed sets: The three modern information and communication channels are almost equally important for all the children of early school age - among the pupils with disabilities the order is: television $-32 \%$, internet $-28 \%$ and mobile phone $-28 \%$. It also is not surprising that $96 \%$ of our respondents used the internet mainly for fun and entertainment.

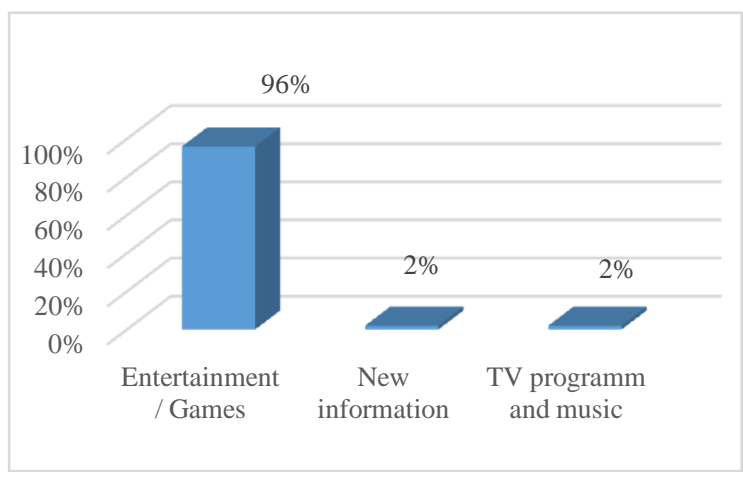

Figure 5: Content sought by the pupils on the internet: cumulative sum for the pupils with communication impairment and the pupils with learning disabilities.

For the pupils the internet was mainly synonymous with entertainment and games - that applied to the healthy population of children at $81 \%$, as well as to the pupils with communication impairment or learning disabilities at a total of $96 \%$. For us a positive surprise was that the early school age children could very well distinguish the pros and cons of internet use. Since most of them go online to play games, their preferred advantages are the possibility to play games, watch films and skype with classmates. The most frequently visited websites are definitely the websites with online games (friv.com and superhry.sk), Facebook, but also YouTube for songs and video clips. Both sets of respondents, the pupils with disabilities as well as the pupils in the first grade of primary school, could also speak about the disadvantages in a rather convincing way:

„, (...) I spend much time there. My parents tell me not to."

„, (...) When I sit for a long time in front of the monitor, my eyes hurt." 
„, (...) There are also things that are not suitable for children."

„, (...) Some strangers can get information about us.,"

„, (...) The internet is sometimes lying."

From the perspective of our objective it was also important to study whether the modern communication technologies change the ways of communication of the pupils with disabilities (Figure $6 \mathrm{a}, 6 \mathrm{~b})$. The results confirmed without any doubts that our respondents expanded their communication options and used the modern forms, such as internet calls, chats, e-mails, etc. We can state that the pupils with communication impairment as well as the pupils with learning disabilities did not have any major problems with becoming familiar with the modern information-communication technologies and actively using them. Certain deviations can be noted for the following forms of communication: $41 \%$ of the pupils with communication impairment favoured personal communication, compared to $31.4 \%$ of the pupils with learning disabilities.

The opposite tendency applied to the use of mobile phones: while only $22.7 \%$ of the pupils with CI preferred this communication tool, in the second group of respondents it was $31.4 \%$. We can come to the conclusion that the pupils with CI can have certain problems with virtual communication without personal contact or when they cannot see the gestures and other forms of non-verbal communication that are an important source of information for them. They need more time to express themselves and need to have also visual information that helps them understand the context. On the other hand, almost $16 \%$ of them use SMS to communicate with their friends and loved ones, compared to $9.8 \%$ of the pupils with learning disabilities. The pupils with CI have more problems with e-mailing; only $7 \%$ preferred this form of communication, compared to $14 \%$ of the pupils with LD.

These different preferences can be explained by the fact that the content as well as the form of an email is more structured, the ideas are formed in more complicated sentences, and because the pupils with communication impairments are less skilled in this area, it can be a problem for them. On the other hand, e-mail communication seems to be very common, since $70 \%$ of the children stated they have their own e-mail address and mailbox

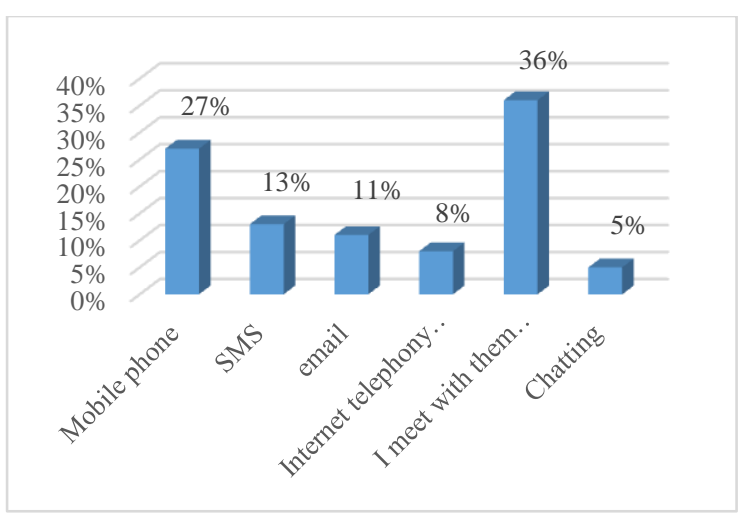

Figure 6a: Communication of the pupils with friends and loved ones. Cumulative sum for the pupils with communication impairment and the pupils with learning disabilities.

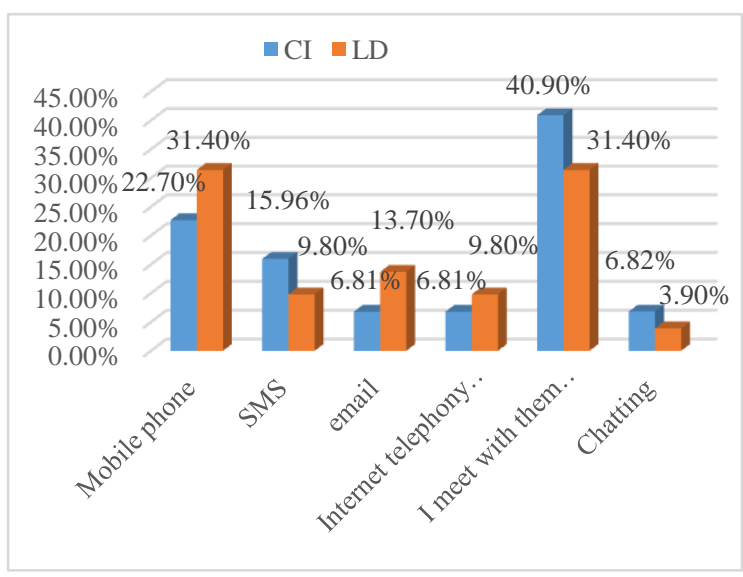

Figure 6b: Communication of the pupils with

friends and loved ones: the pupils with communication impairment and the pupils with learning disabilities

The emergence and mass adoption of mobile phones in the last decade has rapidly changed forms of communication. Brand-new options like chatting, calling via the internet, and others have been introduced. We have noted that the early school age children do not have any problems mastering these new forms of virtual contact, not even the children with disabilities. Despite the existing fears that these new forms of communication would overshadow personal contact, this concern has yet to be proven. One-third of the children claimed that they contact and communicate with their friends and loved ones personally and another third used the mobile phone for this purpose. We did not note any significant differences in the preferences of the primary school pupils, including the pupils with learning disabilities and the pupils with communication impairment. This indicates that the new communication technologies 
generally do not pose any problems even to pupils with disabilities. As shown in the Figure 6a, 6b, they do not have any problems with using the new forms of communication - Skype, chat, etc.

We live in an age of media, therefore we asked all of our respondents to explain what the term „media“ means. Surprisingly, up to $60 \%$ of the pupils with communication impairment were not familiar with this term or were not able to define it, compared to $52 \%$ of the pupils with learning disabilities (Figure 7a, 7b). This rate of unfamiliarity in both cases was very high. Another finding that we consider alarming is that among the pupils in the first grade of the primary school, only $54 \%$ knew the term „media“. However, this does not mean that they can interpret it correctly and fully understand its meaning

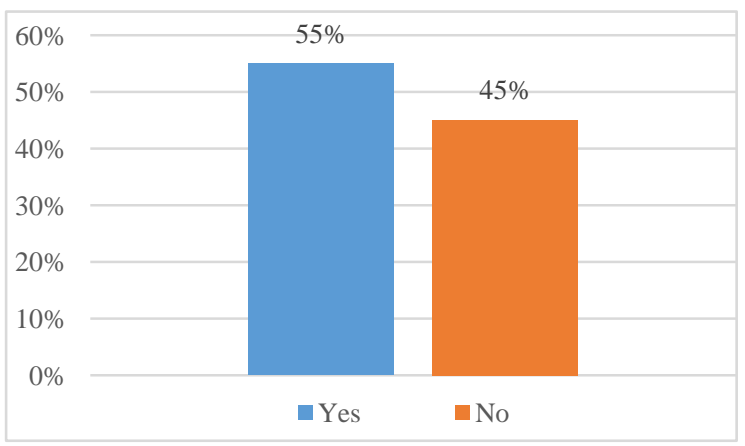

Figure 7a: Interpretation of the term: „Do you know what the term media means?" Cumulative sum for the pupils with communication impairment and the pupils with learning disabilities.

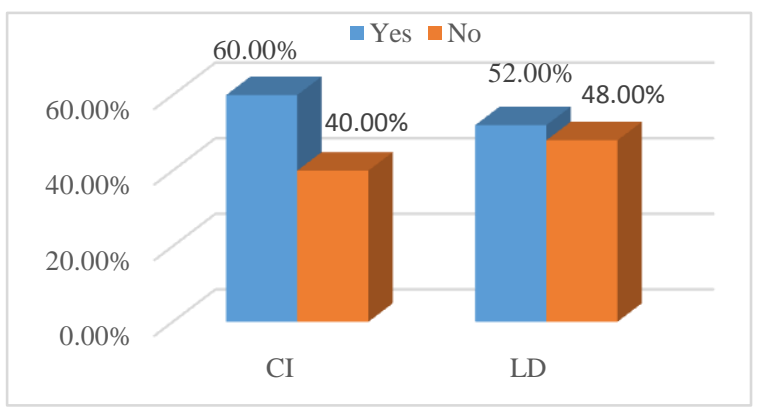

Figure 7b: Interpretation of the term: „Do you know what the term media means?" The pupils with communication impairment and the pupils with learning disabilities.

Here we see quite a big space especially for the school, which should create the space for learning new terms and acquiring new knowledge, to enable the pupils to decipher the media messages they absorb every day. To be media literate means that one is able to select information, evaluate its level and quality and understand its wider context. We consider this one of the key modern competencies of the 21 st century.

\section{Conclusion}

Our survey can be summarised in the following findings: the rate of radio listening in the young generation has been in decline over the last decade. This has been caused by the advent of modern information and communication media, notably the internet and recently also social networks, which absorb a considerable portion of our free time. In general, about one-third of children and young people do not listen to radio broadcasting.

Up to 50 percent of students from the group of those with impaired communication ability doesn't listen to the radio at all. It is the result of poor ability to interpret media messages communicated through words and sounds since they can not imagine real situations under the meaning of words in ether.

Television continues to be a phenomenon when it comes to leisure activities. For pupils in the first grade of primary school it has been a long-term standard to watch television for two or more hours a day. The same applies to the pupils with communication impairment and the pupils with learning disabilities. Children are attracted by television mainly because it offers entertainment and relaxation without requiring any activity and effort.

There was a high preference among children for evening shows broadcast after 8 p. m. - this implies that children are watching evening programmes that are not intended for them. Almost $20 \%$ of the primary school pupils stated in their responses that they regularly watched evening shows. This also indicated that some of the parents allowed their children to „consume“ these programmes and thus take inspiration from the negative patterns (aggression, broken relationships) that appear on the screen. Our survey further showed that the children did not have one favourite TV character with whom they identify on a massive scale. Instead, they had a range of favourite characters.

There is no doubt that the internet has become the phenomenon of this decade. It offers something that other media have not been able to provide: information and amusement, but also communication via social networks; all this in an integrated form under one roof. Again, in general, there were not any considerable differences between respective groups of pupils. All groups were already active on the internet and had the basic skills necessary for orientation in the virtual environment. Our survey showed that up to $41 \%$ of the pupils with 
communication impairment spend between 2 to 3 hours per day online, which is almost double the proportion of the pupils with learning disabilities, at $22.27 \%$. It seems that the pupils with communication impairment were more attracted to the internet and found it more motivating. This could be explained by the fact that compared to the fixed programmes offered by radio or television, on the internet they have the chance to choose the content they prefer. From the perspective of content preferences, we noted that the pupils with communication impairment tended to be more attracted to online action games and YouTube videos than their peers with learning disabilities.

Evaluation of answers to the question about which medium they cannot imagine their lives without did not lead to any surprising conclusions that would deviate from the generally-known trends of recent years. Other surveys have already confirmed that the three media and communication tools that are the most important for all pupils are: television, mobile phone and internet. It also is not surprising that $96 \%$ of our respondents used the internet mainly for fun and entertainment, similarly to the pupils in the first grade of primary school.

For us a positive surprise was that the pupils can very well distinguish the pros and cons of internet use. Since most of them go online to play games, their preferred advantages were the possibility to play games, watch films and skype with classmates. The most frequently visited websites were definitely the websites with online games (friv.com and superhry.sk), Facebook, but also YouTube for songs and video clips. Both groups of respondents, the pupils with learning disabilities as well as the pupils with communication impairment, could also speak about the disadvantages in a rather convincing way.

In general, the new media and modern technologies are changing the ways of communication of children of early school age. The results confirmed without any doubts that our respondents have expanded their communication options and use the modern forms, such as the internet calls, chats, e-mails, etc. We can state that the pupils with disabilities did not have any significant problems with becoming familiar with the modern information-communication technologies and actively using them. In terms of skills and frequency of use, this trend was comparable to the pupils of the first grade of primary school. Certain deviations can be noted for the following forms of communication: $41 \%$ of the pupils with CI favoured personal communication, compared to $31.4 \%$ of the pupils with learning disabilities. The opposite tendency applied to the use of mobile phones: while only $22.7 \%$ of the pupils with CI preferred this communication tool, it was $31.4 \%$ in the second group of respondents. We can come to the conclusion that the pupils with communication impairment can have certain problems with virtual communication without personal contact, when they cannot see the gestures and other forms of nonverbal communication that are an important source of information for them. They probably need more time to express themselves and need to also have visual information that helps them understand the context. However, almost $16 \%$ of this group used SMS to communicate with their friends and loved ones, compared to $9.8 \%$ of the pupils with learning disabilities. The pupils with CI lack the skills needed for e-mail communication; only $7 \%$ preferred this form, compared to $14 \%$ of the pupils with LD. These different preferences can be explained by the fact that the content as well as the form of an e-mail is more structured, the ideas are formed in more complicated sentences, and because the children and pupils with communication impairments are less skilled in this area, it can be a problem for them.

In our research we paid much attention to the pupils with learning disabilities and the pupils with communication impairment, since this target group has been heavily neglected in research related to media literacy. In our country this topic has not yet been examined in detail from a scientific or professional perspective. We also compared our findings with a group of children of early school age who attend primary school. Except for some rather insignificant differences described and commented on above, we can state that the level of media literacy in the pupils from both surveyed sets is very similar, if not identical. The informationcommunication technologies that have introduced new forms of communication in the 21 st century, new information channels and new ways of spending free time, are so user-friendly and easy to handle that they are accessible and available to all age groups. Thus, all children have the opportunity to use and develop their potential within this age of media they are living in.

\section{References}

[1] Barnes, C. (et al). (2007). Final report: Critical media literacy in Ireland. Dublin : The Radharc Trhust 2007. [online]. [cit. 16.04.2014]. Retrieved from: http://www.dublincity.ie/Community/childrensservicesunit /Documents/Critical\%20Media\%20Literacy\%20in\%20Irel and\%20DIT\%202007_sml.pdf. Educational Programme for Pupils with Learning Disabilities ISCED 1 - Primary Education and ISCED 2 - Lower Secondary Education. ŠPÚ 2011. [online]. [cit. 16.04.2014]. Retrieved from: http://www.statpedu.sk/files/documents/svp/1stzs/isced $1 /$ is ced1_spu_uprava.pdf. 
[2] Educational Programme for Children and Pupils with Communication Impairment ISCED 0 - Pre-School Education, ISCED 1 - Primary Education and ISCED 2 Lower Secondary Education. ŠPÚ 2011. [online]. [cit. 16.04.2014]. Retrieved from: http://www.statpedu.sk/files/documents/svp/1stzs/isced1/is ced1_spu_uprava.pdf.

[3] Grunwald deklaration on Media education. Grunwald, 22. január 1982. [online]. [cit. 02.10. 2013]. Retrieved from: http://www.unesco.org.

[4] Guofan, W. (2007). Virtually True / Questioning Online Media. Capstone Press, 2007.

[5] Hardt, H. (2004). Myths for the Masses: An Essay on Mass Commnication. Oxford : Blackwell, 2004.

[6] Hoechsmann, M. - Poyntz, S. (2012). Media Literacies: A Critical Introduction. Buckwell : Publishing, 2012.

[7] Jayson, S. (2009). Are social networks making students more narcissistic? In US Today UP/25/2009 12:23 PM. [online]. [cit. 02.10. 2013]. Retrieved from: http://www.usatoday.com/news/education/2009-08-24narcissism-young_N.htm.

[8] Kupianen, R. (et al.). (2008). Decades of Finish Media Education. Tampere : Tampere University Centre for Media Education, 2008. [online]. [cit. 16.04.2014]. Retrieved from: http://www.mediaeducation.fi/publications/decadesoffinnis hmediaeducation.pdf.

[9] Learning objectives and core contents of education, 2004. Finish National Board of Education, Helsinky. [online]. [cit. 16.04.2014]. Retrieved from: http://www.oph.fi/download/47675_POPS_net_new_2.pdf.

[10] Lenhardt, A., Purcell, K., Smith, A., Zickuhr, K. (2010). Social Media\&Mobile Interenet Use Among Tenns and Young Adults. In Pew Internet. [online]. [cit. 20.12.2013]. Dostupné na internete: http://pewinternet.org/Reports/2010.

[11] McLuhan, M. (1991). Jak rozumět médiím. Praha : Odeon, 1991.

[12] McLuhan, M. (2008). Človek, média a elektronická kultúra. Brno : Jota, 2008.

[13] Metcalfe, J., Simpson, D., Todd, L., Toyn, M. (2013). Thinking Through New Literacies for Primary and Early Years. London : Sage, 2013.

[14] Parry, B. (2013). Children, film and literacy. London : Palgrave Macmillan, 2013.

[15] Potter, W. J. (2012). Media Literacy. SAGE : Publishing, 2012.

Primary School Curriculum. Social, Personal \& Health Education. Dublin : Goverment publication sale office,
1999. [online]. [cit. 16.04.2014]. Retrieved from: http://www.ncca.ie/uploadedfiles/Curriculum/SPHE_Curr. pdf.

[16] Ramonet, I. (1998). [online]. [cit. 20.12. 2013]. Retrieved from: www: http://en.wikipedia.org/wiki/Ignacio_Ramonet.

[17] Roberts, D.F. - Foehr, U. G. (2008). Trends in Media Use. In: The Future of Children. 2008, Vol. 18, N. 1. [online]. [cit. 16.04.2014]. Retrieved from: http://www.princeton.edu/futureofchildren/publications/do cs/18_01_FullJournal.pdf.

[18] Scheibe, C. - Gorow, F. (2012). The Teacher's Guide to Media Literacy: Critical Thinking in a Multimedia World. Corvin a SAGE company 2012.

[19] Silverblatt, A. (2000). Media literacy in an interactive age. 2000. [online]. [cit. 05.03. 2013]. Retrieved from: http://www.readingonline.org/newliteracies/silverblatt/inde x.html.

[20] Study on Assessment Criteria for Media Literacy levels, 2010. Association for Viewers' Interests, Brussels, European. [online]. [cit. 16.04.2014]. Retrieved from: http://www.eavi.eu/joomla/images/stories/Publications/Stu dy2_Assessment/mlstudy2/eavi study_on_assessment_criteria_for_media_literacy_levels_i n_europe.pdf.

[21] Study on Assessment Criteria for Media Literacy Levels, 2009. Project coordinator and editor: Paolo Celot. Scientific coordinator: José Manuel Péres Tornero. Brussels, Oktober 2009. [online]. [cit. 16.04.2014]. Retrieved from: http://ec.europa.eu/culture/media/literacy/docs/studies/eavi _study_assess_crit_media_litlevels_europe_finrep.pdf.

[22] Šupšáková, B. (2013). New Media and Social Networks as a New Phenomenon of Global Access to Information and Education. In: US-China Education Review A, August 2013, Vol. 3, No. 8, pp. 623-635.

[23] Šupsáková, B. (et al). (2012). Umenie \& média vo vzdelávaní 2012. Nové možnosti a výzvy/ Art\&Media in Education 2012. New challenges and opportunities. Bratislava: IRIS. 2012.

[24] Šupšáková, B. (2012). Technological changeover internet age and its effect to social communication youth. In: ICT in Education Desinh Processes, Materials, Resources, diel/Vol.1. Zielona Góra : Oficyna wydawnicza Uniwersytetu Zielonogórskiego 2012.

[25] Tanriverdi, B. - Apak, O. (2010). Analysis of Primary School Curriculum of Turkey, Finland and Ireland in Terms of Media Literacy Education. Educational Sciences: Theory \& Practice, 2010 (2). [online]. [cit. 02.03. 2013]. http://www.eric.ed.gov/ERICWebPortal/recordDetail?accn $\mathrm{o}=\mathrm{EJ} 889203$. 
[26] Thomas, E. - Jolly, St. (2004). Media literacy: A national priority for a changing world. In: American Behavioral Scientist. 2004, Vol. 48, N. 1, 2004, pp. 18-29.

[27] Wilson, C. - Grizzle, A. - Tuazon, R. - Akyempong, K. - Cheung, Ch. (2011). Media and information literacy curriculum for teachers. Paris : UNESCO, 2011. [online]. [cit. 02.03. 2013]. Retrieved from: http://www.unesco.org/new/en/communication-andinformation/resources/publications-and-communicationmaterials/publications/full---list/media-and-informationliteracy-curriculum-for-teachers. 